\title{
Trabalhadores Descartáveis? Condição de Terceirizado e Mal-Estar no Trabalho
}

\section{Disposable workers? Outsourced condition and Mal-Being at Work}

\section{Trabajadores desechables? Condición Outsourced y Mal-Estar en el Trabajo}

\section{Camila Costa Torres*}

Universidade Federal do Rio Grande do Norte - UFRN, Natal, Rio Grande do Norte, Brasil

\section{Mário César Ferreira**}

Universidade Federal do Rio Grande do Norte - UFRN, Natal, Rio Grande do Norte, Brasil

\section{Rodrigo Rezende Ferreira***}

Universidade de Brasília - UnB, Brasília, Distrito Federal, Brasil

\begin{abstract}
RESUMO
Investigar os impactos sobre os trabalhadores do processo de terceirização, que se opera no mundo corporativo, tem sido um desafio importante para as ciências do trabalho e da saúde, especialmente para as organizações. Nesse sentido, objetivou-se nesta pesquisa investigar as fontes de mal-estar no trabalho entre terceirizados em uma Instituição de Ensino Superior brasileira. Considerou-se válidas as respostas de 189 trabalhadores à uma questão aberta do Inventário de Avaliação de Qualidade de Vida no Trabalho (IA_QVT), aplicado por meio de um survey virtual. Utilizou-se o aplicativo IRaMuTeQ, de análise de conteúdo, para o tratamento dos dados e identificou-se os núcleos temáticos estruturadores do discurso dos participantes. Nos resultados, as principais fontes de mal-estar percebidas pelos respondentes foram: (a) tratamento desrespeitoso por parte das outras pessoas e baixo salário; (b) distância casa-trabalho e duração da jornada; e (c) condições de trabalho precárias. A situação é crítica para os terceirizados, que revelam dificuldade de mobilização do coletivo para modificar a realidade. Os achados da pesquisa apontam para a necessidade de intervenção nas causas organizacionais geradoras do mal-estar no trabalho, por meio da formulação de política e de programa de QVT. Eles também fornecem pistas para novos estudos.
\end{abstract}

Palavras-chave: trabalho, terceirização, qualidade de vida no trabalho.

\section{ABSTRACT}

To investigate and understand the impact on workers of the outsourcing process that operates in the corporate world has been a complex and 
important challenge for the field of work and health sciences, especially for organizations. The aim of this research was to investigate the malaise sources at work among outsourced workers in an institution of Brazilian Higher Education. The responses of 189 workers that fulfilled a qualitative question of the Inventory of Quality of Work Life Assessment (IA_QVT), applied through a virtual survey, were considered valid. Data were analyzed using the software IRaMuTeQ, to identify the structuring core themes of participants' speech. The results showed that the main sources of malaise at work perceived by respondents are: (a) disrespectful treatment by other people and low income; (B) distance from home to work and duration of the journey; and (c) poor working conditions. In general, the situation is critical for the outsourced, which, in one point of view, reveal certain difficulty in terms of workers' collective mobilization to change the situation. The research findings points to the need for intervention in organizational causes of the malaise at work, through the conception and implementation of Quality of Work Life (QWL) policies and programs. They also provide clues for further studies.

Keywords: work; outsourcing; quality of work life.

\section{RESUMEN}

Investigar el impacto en los trabajadores del proceso de terceirización que opera en el mundo de la empresa ha sido um desafio importante para las ciencias laborales y de salud, especialmente para las organizaciones. En este sentido, el objetivo general de esta pesquisa fue investigar las fuentes de malestar en el trabajo entre los terceirizados en una institución de educación superior brasileña. Las respuestas válidas de 189 trabajadores a una pregunta aberta del Inventario de Calidad de Vida Laboral de Evaluación (IA_QVT) aplicados a través de una encuesta virtual. La aplicación IRaMuTeQ, de análisis de contenido, permitió identificar los temas centrales del discurso de los participantes. Las principales fuentes de malestar percebidas por los encuestados son: (a) el tratamiento irrespetuoso por otras personas y de bajos ingresos; (b) la distancia de casa al trabajo y la duración del desplazamiento; y (c) las malas condiciones laborales. La situación es crítica para los terceirizados, que revelan dificultad de movilización colectiva para cambiar la situación. Los resultados muestran la necesidad de intervención en las causas organizativas del malestar en el trabajo, a través de la formulación de una politica y uno programa de calidad de vida laboral. También proporcionan pistas para estudios posteriores.

Palabras clave: labor; tercerización; calidad de vida laboral.

\section{I ntrodução}

No limiar do século XXI, a condição de ser trabalhador ou integrar a classe que vive do trabalho, conforme assinala Antunes (2009), implica em uma multiplicidade de modos de vínculos com o mercado de trabalho. Tais modalidades de vínculos - contratos com e sem estabilidade no emprego, contratos temporários, contratos por produtos etc. - ditam os contornos do perfil da vida no trabalho que, por sua vez, são conformadores da condição de ser trabalhador. Atualmente, as diversas formas que configuram essa "condição" 
resultam de transformações que se operam no mundo do trabalho em face do processo de reestruturação produtiva em curso que, do ponto de vista histórico, tem sua origem na década 1965-1975 (Leite, 1994; Baumgarten \& Holzmann, 2011). No caso brasileiro, a possibilidade de mudança do aparato normativo que regula os casos de contratos de terceirização, estendendo esta alternativa para um número maior de empresas, tem gerado intenso debate sobre a sua pertinência ou não (Ferreira, 2015a).

Esse processo vem mudando a paisagem da economia global, merecendo destaque, a título de ilustração, algumas de suas formas de manifestação (Antunes \& Alves, 2004): (a) a mundialização da produção, da distribuição e do consumo; (b) as redes globais de comunicação e informação; (c) a interdependência dos mercados; (d) as inovações tecnológicas nos âmbitos da microeletrônica, da microbiologia e das energias nuclear e ecológica; (e) a redução do ciclo de vida das mercadorias; (f) o crescimento do trabalho autônomo; ( $\mathrm{g}$ ) o desenvolvimento da lean production e das formas de horizontalização do capital produtivo, de modalidades de flexibilização e desconcentração do espaço físico produtivo; (h) a expansão do trabalho em domicílio e do teletrabalho; (i) o aumento do trabalho feminino, especialmente nas modalidades de trabalho part-time, precarizado e desregulamentado; e (j) a escolarização clássica amplia-se para o paradigma da qualificação contínua e a ultraespecialização vem evoluindo para a multiqualificação e a especialização flexível na execução das tarefas, entre outras.

É neste cenário de transformações aceleradas, principalmente econômicas, que a redução do contingente tradicional dos trabalhadores na indústria foi, paulatinamente, cedendo espaço para o crescimento das relações informais e precárias de trabalho, como, por exemplo, são os casos dos subcontratados e os com vínculo empregatício do tipo part-time. Todavia, neste contexto de mudanças cabe destacar que o fenômeno da terceirização da economia tem sido também acompanhado do aumento da terceirização generalizada de serviços. O paradigma da flexibilização dos processos produtivos (Sennett, 2012) tem sido a ferramenta conceitual estratégica que serve de "carro-chefe" do processo das mudanças em curso. De fato, o seu uso visa, entre outras perspectivas, tornar os trabalhadores mais resilientes quanto aos imperativos econômicos impostos pelo estágio atual do capitalismo globalizado, especialmente para suportarem as adversidades existentes nos contextos organizacionais.

Investigar e compreender cientificamente os impactos sobre os trabalhadores deste processo global, acelerado e intenso que se opera no mundo do trabalho embalado pela reestruturação produtiva se coloca com um desafio complexo para o campo das denominadas ciências do trabalho e da saúde. 
Os indicadores apresentados pela Organização Internacional de Trabalho (OIT, 2013) sobre a saúde e a segurança nos contextos organizacionais revelam que os impactos do processo reestruturação produtiva não são "indolores" para os trabalhadores. Eles mostram, por exemplo, que: (a) cerca de 2,34 milhões de pessoas morrem vítimas de acidentes ou doenças relacionadas com o trabalho, sendo que a maioria absoluta das vítimas - por volta de 2,03 milhões perde a vida devido a uma das diversas enfermidades profissionais existentes; (b) cerca de 6.300 mortes diárias relacionadas com o trabalho e estima-se que cerca de 5.500 delas são provenientes das diferentes doenças do trabalho; (c) a incidência Transtornos Musculoesqueléticos (TME) em diversos países se constituem no tipo de enfermidade mais recorrente: em 27 estados membros da União Europeia, os TME são os de maior prevalência; (d) os casos de estresse laboral estão relacionados com o assédio moral, sexual e a violência psicológica no trabalho e ele tem contribuído sobremaneira para o uso abusivo de álcool e o consumo de drogas; e (e) a vivência do estresse excessivo revela evidências clínicas de associação com problemas cardíacos, patologias musculoesqueléticas e digestivas.

O conhecimento parcial de tais indicadores - é sabido que os dados de acidentes e doenças são, por razões diversas, subnotificados mostra um cenário inquietante e, a rigor, dramático dos efeitos da reestruturação produtiva. Em certa medida, não é exagero afirmar que, de fato, conhecemos tão-somente a "ponta do iceberg" da real extensão do problema existente nos contextos de trabalho. Em se tratando de trabalhadores com situações de emprego mais estáveis e vínculos de trabalho mais duradouros, por exemplo, no Brasil o caso de celetistas de grande parcela do setor privado e concursados no setor público, há, pelo menos, mais estudos e pesquisas produzidas sobre a relação trabalho e saúde com diversas categorias profissionais, entre elas servem de ilustração os casos: dos bancários (Finazzi-Santos \& Siqueira, 2011; Santos, Siqueira, \& Mendes, 2011); dos professores (Calderón, 2013; Lago, Cunha, \& Borges, 2015); dos policiais (Bezerra, Minayo, \& Constantino, 2013; Jesus, Mota, \& Jesus, 2014); e dos profissionais de saúde (Magalhães et al., 2015; Schmidt, Paladini, Biato, Pais \& Oliveira, 2013).

No caso brasileiro, entretanto, o conhecimento sobre a relação entre trabalho e saúde com os trabalhadores terceirizados é relativamente escasso sobre o perfil deste segmento. Pouco ou nada se sabe, no campo da Psicologia Organizacional e do Trabalho, sobre suas condições de trabalho e suas vivências nos contextos organizacionais das ocupações terceirizadas no Brasil. Fica-se com a impressão de que no rol de prioridades de objetos e temas a serem investigados, os pesquisadores de áreas diversas operam uma "terceirização" de prioridades quando se trata de estudar o trabalho terceirizado no que tange às questões de saúde e do bem-estar. Conhecer a realidade de 
trabalho das categorias profissionais nessa condição e, sobretudo, como eles avaliam os contexto nos quais eles estão inseridos pode produzir contribuições relevantes para os campos da vigilância sanitária, da assistência e da promoção da Qualidade de Vida no Trabalho (QVT).

O presente artigo, de natureza empírica, traz o relato dos resultados de uma pesquisa sobre Qualidade de Vida no Trabalho (QVT), realizada com trabalhadores terceirizados em um órgão público federal brasileiro - universidade pública - tendo como objetivos: (a) descrever quais são as principais fontes de mal-estar no trabalho identificadas pelos trabalhadores terceirizados; (b) apontar quais são os elementos constituintes das fontes de mal-estar no trabalho com base nas falas destes trabalhadores; e (c) identificar qual é grau de importância hierárquica, em termos quantitativos, das fontes de malestar no trabalho expressas pelos participantes da pesquisa.

O alcance de tais objetivos pode contribuir para avançar no conhecimento sobre a condição de trabalhador terceirizado no Brasil, nos campos da Psicologia Organizacional, do Trabalho, e da Ergonomia da Atividade, e também fornecer subsídios para a formulação de políticas tanto públicas quanto organizacionais, para uma transformação positiva da realidade destes trabalhadores.

\section{Terceirização: o que é, como começou, seus efeitos}

O processo de terceirização encontrou solo fértil no cenário da reestruturação produtiva em função das importantes alterações ocorridas sob as formas técnicas de organização da produção e das formas sociais (como a situação do desemprego) a ela subjacentes. A busca pela flexibilidade dos novos modelos produtivos, como também do aumento da produtividade nas fábricas, das novas estratégias de competição adotadas pelas empresas, propiciou a introdução de mecanismos de redução do trabalho vivo nos complexos produtivos. Entre esses mecanismos, está a terceirização, utilizada como estratégia empresarial de competição, baseada na redução de custos relacionados com a força de trabalho (Barreto, Leone, Reis, \& Rocha Neto, 2015; Cardoso \& Romão, 2011; Marcelino \& Cavalcante, 2012). Em outros países do mundo, há mais de uma forma de se compreender e denominar o processo chamado de terceirização (p.ex. externalização), contudo, no Brasil, tem sido mais comum considerar a terceirização como todo processo de contratação de trabalhadores por empresa interposta (Marcelino, 2007).

Nesta concepção há um destaque para as relações empregatícias, visto que segundo a análise realizada por Marcelino (2007), o que há de mais estável nessas relações é exatamente o vínculo por meio de contrato, pois todo resto é muito fluido, como a definição de atividade-fim e atividade-meio, a real capacidade técnica das 
empresas subcontratadas, a noção de parceria e a ideia de que a terceirização garante qualidade.

Acompanhando parcialmente esta perspectiva, Garcia (2011) propõe que a terceirização é um recurso gerencial pelo qual uma empresa transfere para outra, por meio de contrato, parte da sua atividadefim, seja ela industrial, de serviços ou agroindustrial, na expectativa de tornar mais flexíveis a organização e as relações de trabalho, desenvolvendo uma maior especialização das atividades. A "empresa terceira", segundo este autor, pode operar dentro ou fora dos limites físicos da contratante, interna ou externamente, mantendo necessariamente independência administrativa e de capital.

A partir da década de 1980, no Brasil, nota-se o incremento das terceirizações e elas se tornam um dos mais importantes recursos estratégicos das empresas para gestão e redução dos custos com pessoal, apresentando um caráter defensivo e restritivo com relação aos trabalhadores (Barreto et al., 2015; Garcia, 2011; Marcelino, 2007).

A estratégia promete a redução de custos, mas não somente isso, pois como constata Marcelino (2007), a terceirização transforma relações que seriam trabalhistas (contratação de pessoal) em relações comerciais (contrato entre empresas), e essa mudança acaba estabelecendo uma nova realidade nas organizações, que passam a ter um contrato existente entre elas, que se propõe capaz de regular as relações entre duas diferentes culturas organizacionais e diferentes políticas, buscando administrar diferentes exigências.

Marcelino (2007) reforça a existência de mais de um tipo de terceirização, mas independente do tipo, cabe salientar que sua ampla difusão no Brasil foi possível graças a sua eficiência em contornar dois problemas existentes: a diminuição das taxas de lucro e a necessidade de recomposição do domínio sobre as classes trabalhadoras. A terceirização tornou-se uma forma de simplificação dos contratos de trabalho, de elevada rotatividade, contida remuneração e longa jornada de trabalho, afetando não apenas as questões econômicas, mas, também, a organização política dos trabalhadores.

Para Cardoso e Romão (2011) a estratégia da terceirização é baseada na exclusão e precarização da força de trabalho pela via da intensificação de mecanismos de subcontratação. Isto pode ser verificado por meio do aumento da incidência do retrabalho, o número de acidentes, das multas trabalhistas, da elevada perda de homens/hora, quer seja por acidente, absenteísmo ou mobilizações de natureza sindical.

No debate atual sobre terceirização destacam-se duas teses: (a) as terceirizações implicam em novas formas de trabalho e emprego precário, visto que geram uma maior instabilidade dos vínculos dos trabalhadores com as empresas terceiras, onde houve uma notável 
redução de garantias e de direitos dos trabalhadores, no que se refere ao emprego e às condições de saúde e segurança no trabalho; e (b) as terceirizações comportariam formas heterogêneas de trabalho e emprego que podem, em certas condições, criar boas oportunidades às pequenas empresas e aos trabalhadores (Garcia, 2011).

Uma tese não necessariamente descarta a outra, posto que existem várias formas de terceirização, mas a pesquisa empírica que embasa o presente artigo revela alinhamento com a primeira tese, identificando, segundo a perspectiva dos trabalhadores, as consequências negativas da condição de terceirizado.

Essa condição merece destaque no momento atual, no qual tramita no Congresso Nacional Brasileiro o polêmico Projeto de Lei n. 4330, que dispõe sobre os contratos de terceirização e as relações de trabalho deles decorrentes. Neste projeto de lei, identifica-se que em relações de terceirização muitas responsabilidades se estabelecem entre as empresas, contratante e contratada, mas também envolvendo as entidades de representação dos trabalhadores, os sindicatos e associações e os próprios trabalhadores. Nota-se a existência de exigências de fiscalização dos contratos e a demanda de um acompanhamento dos mesmos, que dificilmente se realiza na atualidade.

Contudo, o teor que predomina no projeto de lei é de regulação das relações econômicas, das garantias, das taxas, das responsabilidades financeiras. Pode-se dizer que é uma legislação muito mais voltada para as questões econômicas que trabalhistas, deixando a desejar no olhar daqueles que defendem os trabalhadores e seus direitos (Projeto de Lei n. 4330).

As consequências para os trabalhadores e para a sociedade das relações instáveis de trabalho estabelecidas pela terceirização e os contextos precários se revelam, principalmente, nos altos índices de adoecimento, acidentes e mortes no trabalho, como constatado nos indicadores da OIT (2013), mas não somente, pois além das questões de saúde, há também outros efeitos negativos para sociedade, como serviços de baixa qualidade e a cidadania em risco (Barreto et al., 2015; Hirata, 2011; Miranda, 2010).

Diante disso, propomos a análise da condição de terceirizado e sua perspectiva sobre as fontes de mal-estar no trabalho, tendo como referencial de interpretação as proposições da Ergonomia da Atividade Aplicada a Qualidade de Vida no Trabalho - EAA_QVT. Trata-se de uma abordagem brasileira que vem se dedicando à compreensão e transformação dos contextos de trabalho pela via da promoção da QVT, embasada no olhar dos trabalhadores.

\section{EAA_QVT: enfoque teórico metodológico para abordar o mal- estar no trabalho}


A Ergonomia da Atividade Aplicada à Qualidade de Vida no Trabalho EAA_QVT, proposta por Ferreira (2008, 2011, 2012, 2015b) tem como referencial teórico-metodológico maior a Ergonomia da Atividade (Laville, 1993; Wisner, 1984, 1994), uma abordagem científica antropocêntrica fundamentada em conhecimentos interdisciplinares das ciências humanas e da saúde, que visa compatibilizar o contexto sociotécnico de trabalho aos objetivos e necessidades do sujeito e/ou grupo, bem como às exigências das tarefas e das situações de trabalho (Ferreira \& Torres, 2015).

A EAA_QVT distingue-se dos modelos convencionais de promoção da QVT, de caráter assistencialista que, geralmente, têm como escopo o incremento da produtividade, conquistado por meio do investimento em intervenções sobre os indivíduos trabalhadores, pela via da oferta de atividades do tipo antiestresse (ex. massagens, yoga etc.), que, a rigor, objetivam aumentar a resiliência dos trabalhadores.

Nesta abordagem, a QVT é vista sob duas perspectivas interdependentes (Ferreira, 2012, itálicos nossos):

(a) sob a ótica das organizações, a QVT é um preceito de gestão organizacional que se expressa por um conjunto de normas, diretrizes e práticas no âmbito das condições, da organização e das relações socioprofissionais de trabalho que visa à promoção do bem-estar individual e coletivo, o desenvolvimento pessoal dos trabalhadores e o exercício da cidadania organizacional nos ambientes de trabalho; e (b) sob a ótica dos trabalhadores, ela se expressa por meio das representações globais (contexto organizacional) e específicas (situações de trabalho) que estes constroem, indicando o predomínio de experiências de bem-estar no trabalho, de reconhecimentos institucional e coletivo, de possibilidade de crescimento profissional e de respeito às características individuais (p. 172).

Além do conceito de QVT sob a ótica das organizações e dos trabalhadores, outras duas noções são fundamentais nesta perspectiva teórica para se compreender e transformar as situações de trabalho, as noções de bem-estar e mal-estar no trabalho expressas nas representações e nos relatos dos trabalhadores (Ferreira \& Torres, 2015). Tais noções revelam-se basilares para as proposições de intervenção advindas desta abordagem.

Segundo Ferreira (2012, itálicos nossos):

O bem-estar no trabalho é um sentimento agradável que se origina das situações vivenciadas pelo(s) indivíduo(s) na execução das tarefas. A manifestação individual ou coletiva do 
bem-estar no trabalho se caracteriza pela vivência de sentimentos (isolados ou associados) que ocorrem, com maior frequência, nas seguintes modalidades: alegria, amizade, ânimo, confiança, conforto, disposição, equidade, equilíbrio, estima, felicidade, harmonia, justiça, liberdade, prazer, respeito, satisfação, segurança, simpatia. A vivência duradoura deste sentimento pelos trabalhadores constitui um fator de promoção da saúde nas situações de trabalho e indica a presença de Qualidade de Vida no Trabalho (QVT) (p. 179).

O mal-estar no trabalho é um sentimento desagradável que se origina das situações vivenciadas pelo(s) indivíduo(s) na execução das tarefas. A manifestação individual ou coletiva do mal-estar no trabalho se caracteriza pela vivência de sentimentos (isolados ou associados) que ocorrem, com maior frequência, nas seguintes modalidades: aborrecimento, antipatia, aversão, constrangimento, contrariedade, decepção, desânimo, desconforto, descontentamento, desrespeito, embaraço, incômodo, indisposição, menosprezo, ofensa, perturbação, repulsa, tédio. A vivência duradoura deste sentimento pelos trabalhadores constitui um fator de risco para a saúde nas situações de trabalho e indica a ausência de Qualidade de Vida no Trabalho (QVT) (p. 180-181).

A aplicação da EAA_QVT tem como perspectiva a prevenção das vivências de mal-estar no trabalho e focando em intervenções nas origens dos problemas, geralmente encontradas em questões relacionadas: (a) ao contexto de trabalho, que inclui as variáveis (antecedentes) "condições e organização do trabalho, relações socioprofissionais, reconhecimento e crescimento profissional"; e (b) às variáveis (consequentes) "desgastes; afetos positivo e negativo"; e (c) à variável (moderadora) práticas de gestão. Isso só tem sido possível por meio do conhecimento do olhar dos trabalhadores, das representações que eles constroem sobre suas realidades de trabalho e seus efeitos.

É com base nessa perspectiva, a EAA_QVT, que as representações de mal-estar dos trabalhadores terceirizados serão interpretadas aqui.

Para investigar o tema do presente artigo e contemplar os objetivos delineados, as seguintes questões orientaram a condução da pesquisa: (a) Quais são as principais fontes de mal-estar no trabalho identificadas pelos trabalhadores terceirizados no órgão público investigado; (b) Quais são os elementos constituintes das fontes de mal-estar no trabalho; e (c) Qual é grau de importância hierárquica, em termos quantitativos, das fontes de mal-estar no trabalho apontadas pelos participantes da pesquisa. Tais questões estruturaram o delineamento metodológico adotado na pesquisa. 


\section{Método}

O estudo se orientou pela abordagem metodológica da EAA_QVT, tal qual proposta por Ferreira $(2009,2011,2012)$, interessando aqui especificamente a etapa de diagnóstico macroergonômico, na qual se utiliza um inventário de natureza quantitativa e qualitativa.

A pesquisa foi realizada em uma Instituição de Ensino Superior (IES), de natureza pública, situada na região nordeste do Brasil, de grande porte, com sede na capital do estado e outros campi situados no interior. Contando com mais de 60 cursos de graduação, e mais de 50 cursos de pós-graduação (mestrado e doutorado) em 2010.

\subsection{Participantes}

A pesquisa teve intenção censitária, sendo disponibilizada a todos os trabalhadores da universidade (servidores efetivos, estagiários e terceirizados). Do total, participaram e foram considerados válidos para análise 189 terceirizados, o equivalente a 15,08\% dos respondentes $(\mathrm{N}=1.635)$, compondo, então, o público alvo que é o foco neste artigo. Os dados foram coletados no período de outubro a dezembro de 2014 e o perfil resumido dos participantes se caracteriza por: uma discreta predominância do sexo masculino ( masculino $=52,9 \%$ e feminino $=46,6 \%)$; idades variando de 19 a 62 anos (média de 35,35 anos e DP $=9,82$ ); estado civil predominante casado $(39,2 \%)$; com média tempo de trabalho na instituição de 4,69 anos ( $D P=5,87$ ); lotados na capital e no interior, com participação mais expressiva dos lotados na capital $(89,2 \%)$; e escolaridade bastante diversificada, variando do ensino fundamental completo ao mestrado, predominando o médio completo $(25,9 \%)$.

\subsection{I nstrumento}

Utilizou-se o Inventário de Avaliação de Qualidade de Vida no trabalho (IA_QVT, Ferreira, 2009), que é um instrumento de natureza quantitativa (escala psicométrica do tipo Likert, alfa 0,94) e qualitativa (quatro questões abertas), que permite conhecer o que pensam os respondentes sobre a Qualidade de Vida no Trabalho. Considerando o recorte temático do presente artigo, conforme ilustra o seu próprio título, utilizou-se apenas os resultados obtidos em uma das quatro questões qualitativas do instrumento, a saber: "Quando penso no meu trabalho na IES, o que me causa mais mal-estar é...". A aplicação do inventário realizou-se somente no formato digital, visando garantir a confidencialidade dos dados dos respondentes e a presteza da coleta. O IA_QVT era acessado pelos participantes após a leitura de uma tela inicial de instruções que continham: objetivo da pesquisa, importância da participação e responsabilidade acadêmica. 
A tela inicial também explicitava, com base nas orientações da Resolução MS196/96, do Conselho Nacional de Saúde, diretrizes éticas relativas: (a) à participação voluntária; (b) à possibilidade de desistência em participar a qualquer tempo sem acarretar nenhum prejuízo ou dano pessoal; (c) à inexistência de riscos para as atividades de trabalho ou para o órgão; (d) ao sigilo ético no tratamento dos resultados e (e) à liberdade para não se identificar. Somente após a leitura e ter clicado na opção "Estou de acordo em participar", era possível o participante acessar o campo para a entrada do código pessoal para responder o IA_QVT. Ao final do preenchimento do questionário, o participante deveria acionar comando para salvar os dados.

\subsection{Procedimentos de Coleta de Dados e Tratamento}

A pesquisa em questão passou, primeiramente, por aprovações internas na universidade, tendo sido aprovada a sua realização pela Pró-reitoria de Gestão de Pessoas, definindo-se todos os trabalhadores da universidade como público-alvo. Em seguida, foram constituídas uma equipe acadêmica e um Grupo de Trabalho - GT da organização e, neste caso, composto por profissionais da IES, responsáveis por realizar etapas prévias de divulgação, encaminhamento para o comitê de ética e sensibilização dos participantes, bem como de fornecer os dados do perfil demográfico/profissiográfico para a devida adaptação do IA_QVT. A coleta de dados aconteceu de outubro a dezembro de 2014, via internet, tendo sido distribuídos códigos impressos confidenciais para o acesso ao instrumento. Houve monitoramento diário da participação dos respondentes com base nos dados profissiográficos (ex. lotação, cargo), e quando necessário, houve reforço da divulgação da pesquisa e prestação de esclarecimentos ao público alvo. 0 tratamento dos dados foi feito por meio dos núcleos temáticos estruturadores do discurso dos respondentes, com auxílio de software IRaMuTeQ (Ratinaud, 2009). Trata-se de um aplicativo gratuito, que trabalha em interface com o software $R$, possibilitando diversas formas de análises estatísticas de corpus textuais e tabelas de indivíduos por palavras. Utilizou-se do IRaMuTeQ para realizar uma análise de classificação hierárquica descendente e nuvem de palavras.

Ao término do tratamento de dados foram realizadas devolutivas para os gestores e trabalhadores da IES visando validar os resultados obtidos e ampliar as bases de interpretação dos achados. 


\section{Resultados}

Um primeiro resultado que chama a atenção, obtido com o uso do aplicativo IRaMuTeQ, foi identificar a "nuvem de palavras", ou seja, quando mais mencionada uma determinada palavra nas falas dos participantes, ao responderem à questão "Quando penso no meu trabalho, o que me causa mais mal-estar é...", maior o seu tamanho na representação gráfica. A Figura 1 mostra este resultado.

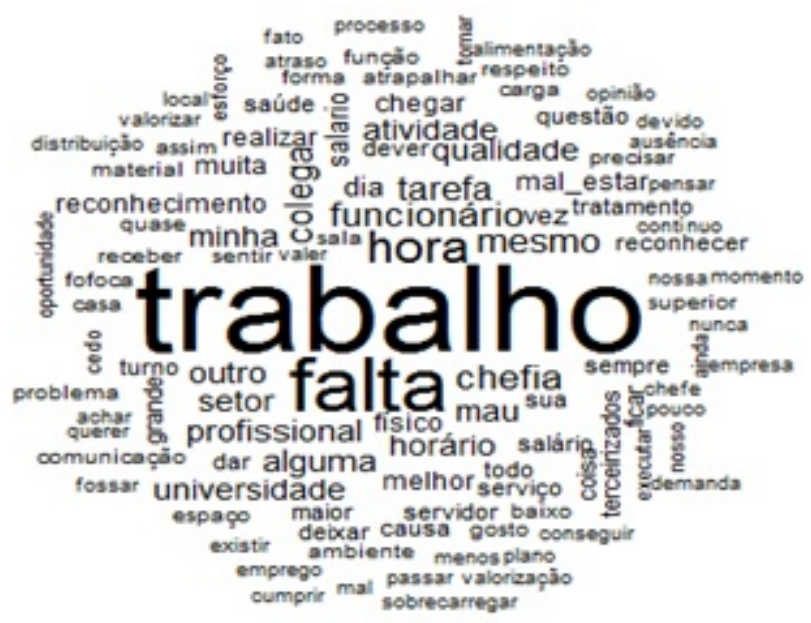

Figura 1 - Nuvem de Palavras Estruturadoras das Fontes de Mal-Estar no Trabalho (Fonte: Os autores)

Na figura 1, as palavras que aparecem maiores são: trabalho, falta, hora. Em seguida, em tamanho menor, porém nítidas, as palavras: funcionário, chefia, tarefa, entre outras, como colega, atividade, mau. Essas são as palavras estruturadoras das fontes de mal-estar para os trabalhadores terceirizados. Esse resultado revela que as fontes de mal-estar estão fortemente relacionadas com o trabalho (trabalho, tarefa, atividade), com as pessoas (chefia, colega), e ainda, com sentimentos negativos e horário (falta, hora, mau). Mostrando relação também com os núcleos temáticos estruturadores do discurso.

O tratamento dos dados identificou três núcleos temáticos estruturadores no discurso dos terceirizados. Estes núcleos são os seguintes: (a) "Tratamento Desrespeitoso e Baixo Salário" (37,21\%); (b) "Condições de Trabalho Precárias" (27,91\%); e (c) "Distância Casa-Trabalho e Duração da J ornada (34,88\%)". A Figura 2 ilustra a distribuição dos núcleos temáticos. 


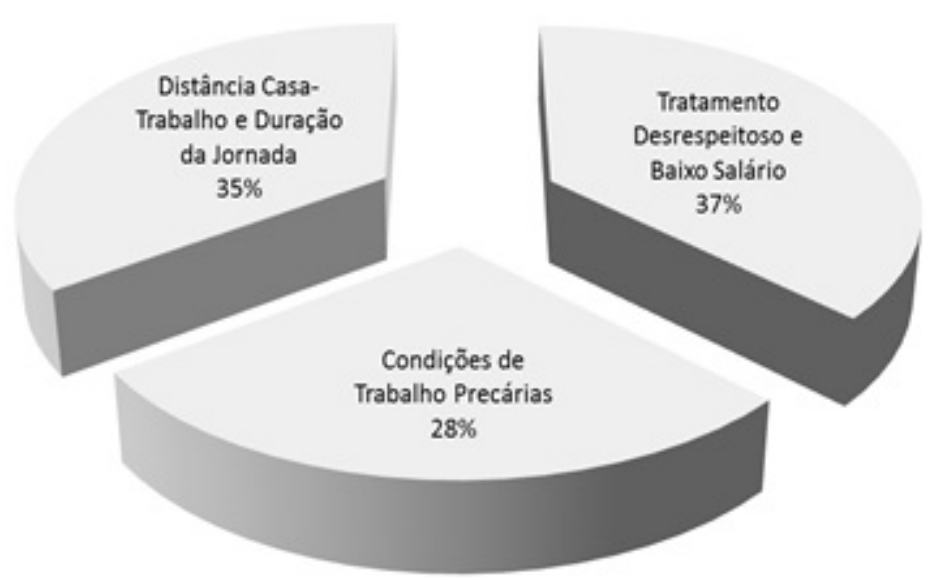

Figura 2 - Classes Temáticas Estruturadoras das Representações dos Terceirizados das Fontes de Mal-Estar no Trabalho (Fonte: Os autores)

Quando os terceirizados abordam estas temáticas do que efetivamente eles estão tratando? Quais são os aspectos que constituem efetivamente o discurso dos terceirizados? Vejamos, portanto, as frases mais representativas de cada um dos núcleos temáticos identificados no tratamento dos dados.

No que concerne à classe temática "Tratamento Desrespeitoso e Baixo Salário" (37,21\%), as falas mais são as seguintes (grifos nossos): “(...) desrespeito daqueles que estão acima eles acham que por sermos terceirizados não somos iguais"; “(...) alguns funcionários da universidade zombam muito da nossa capacidade. Eu acho que nós terceirizados deveríamos ser mais respeitado sou muito feliz porque tenho o meu emprego ganho o sustento para da minha família agradeço por essa oportunidade que pelo menos nos faz sentir alguma coisa"; "queria que esta universidade fosse um pouco mais rigorosa em questão de espaço de trabalho... ex-alunos e também funcionários não fizessem o que bem entende no meu espaço de trabalho"; "o salário que não tem um aumento justo"; e "salário baixo".

No que tange à classe temática "Distância Casa-Trabalho e Duração da Jornada", as falas que a ilustram são as seguintes: "a distância de casa até aqui o trânsito e o horário de saída do trabalho muito tarde 17horas 30min"; "a distancia de casa para o trabalho"; "a rotina massacrante a obrigação de exercer a função durante oito horas por dia"; "não temos mais tempo para lazer esporte e outras coisas que precisamos resolver durante o dia saímos às 7 horas de casa e voltamos às 19 horas enfrentando trânsito caos"; e "ficar 8 horas longe da minha filha".

Finalmente, a classe temática "Condições de Trabalho Precárias" pode ser melhor compreendida com base nas seguintes falas: "falta de material para execuções dos serviços"; "quando eu fico impedido de executar um serviço por falta de materiais e ferramentas"; "alta da 
cantina no prédio onde trabalho"; "não existir um posto de trabalho especifico para instalação dos vigilante"; e "a cadeira que precisarei sentar quando chegar no ambiente de trabalho a falta de ergonomia". Tais núcleos expressam as principais fontes de mal-estar no trabalho, identificados entre os terceirizados. Tais achados possibilitaram alcançar os três objetivos delineados pela pesquisa e igualmente responder às questões norteadoras.

\section{Discussão}

As falas dos trabalhadores terceirizados são repletas de representações e significados que não estão situados apenas na atualidade, o cenário contemporâneo do mundo do trabalho. Inevitavelmente, elas trazem em si marcas de outros momentos históricos, de outras realidades vividas, que se atualizam em pleno século XXI com as novas formas de gestão do trabalho.

Quando os trabalhadores terceirizados mencionam, por exemplo, a forma desrespeitosa com que são tratados, em $37,21 \%$ do discurso, sendo essa uma das principais fontes de mal-estar, eles se referem a distância criada entre concursados e terceirizados no serviço público, como um distanciamento entre trabalhadores. Tal fato permite perceber um inequívoco resquício de uma parte bastante cruel da história brasileira, que foi o período da escravidão, em que aqueles que detinham menos condições eram explorados ao máximo e, em muitos casos, não eram sequer tratados como humanos. Nessa linha de reflexão, analisando a situação dos trabalhadores terceirizados no Brasil, Ferreira (2015a) recorda a obra clássica do sociólogo Gilberto Freire, intitulada Casa grande \& Senzala. Ferreira questiona se o trabalho terceirizado seria, em certa medida, a face moderna do período escravagista brasileiro, e também alerta que, apesar dos concursados não estarem exatamente gozando as benesses da "Casa Grande", pois eles também carecem de boas condições e de QVT, os terceirizados infelizmente aproximam-se das vivências experimentadas na "Senzala".

O que agrava a situação é que a queixa do desrespeito não está isolada, ela vem associada com "Baixos Salários", "Distância CasaTrabalho e Duração da Jornada" e "Condições de Trabalho Precárias". Essa associação de condições negativas realmente nos leva a constatar o quão desagradável e imprópria tem sido a condição de trabalhador terceirizado no Brasil. A satisfação por ter um emprego e ele garantir a dignidade do trabalhador e sua família existe, mas é uma satisfação frágil quando comparada com os elementos negativos vivenciados. Tais resultados obtidos na pesquisa também aparecem em outras investigações (Barreto et al., 2015; Hirata, 2011; Marcelino \& Cavalcante, 2012; Miranda, 2010). 
Os trabalhadores terceirizados se queixam de ter seu tempo praticamente todo consumido pelo trabalho e pelo deslocamento casa-trabalho-casa, mais uma vez se assemelhando ao sistema escravista em que a diferença entre o tempo de trabalho e o tempo de não trabalho era quase nula. Por analogia possível, cabe lembrar que os escravos tinham pouco ou quase nenhum tempo destinado ao não trabalho, que permite as atividades criativas, de lazer e de repouso (Dal Rosso, 2011).

Cabe assinalar a situação nada favorável para os terceirizados, que também é uma queixa que afeta a todos os tipos de trabalhadores na atualidade, a precarização do trabalho, que pode se manifestar pela redução dos direitos dos trabalhadores, pela instabilidade dos vínculos de trabalho e também pela falta de qualidade no exercício da atividade (Galeazzi \& Holzmann, 2011). As exigências são muitas, os riscos também, pois as condições são precárias e não favorecem o desempenho com a preservação da saúde e a segurança. Neste contexto, os trabalhadores precisam investir mais de si, dos seus corpos, da sua cognição e de todas as suas capacidades para alcançar a produtividade almejada.

As consequências negativas de tal contexto aparecem com o tempo, visto que, comumente, se alcança a produtividade, mas ela acaba trazendo consigo um desgaste significativo dos trabalhadores, os altos índices de adoecimentos, de acidentes e até mortes no trabalho, como já mencionado pelos indicadores da OIT (2013). Isto foi apresentado, por exemplo, pela recente pesquisa de Barreto et al. (2015) com trabalhadores terceirizados, revelando como principais resultados o custo humano físico grave e uma sensível predominância de sofrimento.

A situação é crítica para os terceirizados, que revelam certa dificuldade de mobilização do coletivo para modificar as situações de trabalho e, ao mesmo tempo, os efeitos negativos que elas produzem afetam todas as categorias de trabalhadores, pois não há como restringi-los a um ambiente ou grupo de pessoas. Nota-se, portanto, um efeito combinado das fontes de mal-estar o que agrava a situação e a condição de terceirizado. As políticas públicas, principalmente de saúde, que deveriam dar suporte a esses trabalhadores também se mostram residuais ou ausentes, configurando um cenário conturbado e prejudicial no caso brasileiro.

Cabe apontar que apesar de todos os 1.635 trabalhadores terceirizados da IES terem sido convidados a participar do estudo, apenas 189 efetivamente participaram, o que pode ser um número baixo de adesão, mas que certamente não diminui a importância dos resultados apresentados. Isto também se constitui em um alerta para a necessidade de mais estudos e mais aprofundamento nas questões relativas aos trabalhadores terceirizados. Em certa medida, os achados encontrados na pesquisa parecem mostrar a "ponta do 
iceberg" dos problemas vivenciados pelos terceirizados. Os resultados aqui apresentados evidentemente não autorizam uma generalização, mas revelam um case que abre favorece a interlocução com outras pesquisas sobre a condição dos trabalhadores terceirizados no Brasil. Uma pista fecunda para investigações futuras consiste em buscar respostas para duas questões pertinentes: (a) como se dá a gênese dos principais problemas enfrentados pelos terceirizados?; (b) de que forma eles lidam com os problemas vivenciados para, ao mesmo tempo, garantir a execução das tarefas e preservar a própria saúde e a segurança no trabalho? (c) quais seriam os possíveis contrapontos com as fontes de bem-estar vivenciadas? Por fim, tanto o aumento de estudos quanto os níveis de aprofundamento poderão contribuir, numa perspectiva aplicada, para resgatar o sentido humano do trabalho e tornar algo de um passado lastimável frases como a de uma participante desta pesquisa: “(...) saber que a dedicação de nada importa na hora de ser demitida ou jogada fora como um copo descartável".

\section{Referências}

Antunes, R. (2009). Os sentidos do trabalho - Ensaio sobre a afirmação e a negação do trabalho. São Paulo: Boitempo.

Antunes, R., \& Alves, G. (2004). As mutações no mundo do trabalho na era da mundialização do capital. Educação \& Sociedade, 25(87). Recuperado em 05 de novembro de 2011, de http: //www.scielo.br/scielo.php?script=sci_arttext\&pid=S010173302004000200003\&lng=pt\&nrm=iso. doi: 10.1590/S010173302004000200003

Barreto, L. K. da S., Leone, N. M. de C. P. G., Reis, S. B. dos, \& Rocha Neto, M. P. da (2015). Prazer e sofrimento em empresa terceirizada. Revista Raunp, 7(1), 67-76.

Baumgarten, M., \& Holzmann, L. (2011). Reestruturação produtiva. In A. D. Cattani \& L. Holzmann (Orgs.), Dicionário de Trabalho e Tecnologia (pp. 315-319). Porto Alegre: Zouk.

Bezerra, C. de M., Minayo, M. C. de S., \& Constantino, P. (2013, março). Estresse ocupacional em mulheres policiais. Ciência \& Saúde Coletiva, 18(3), 657-666. doi: 10.1590/S141381232013000300011

Calderón, A. I. (2013). Terceirização do trabalho docente à luz da responsabilidade social da educação superior. Trabalho, Educação \& Saúde, 11(3), 487-501. Recuperado em 01 de junho de 2015, de http: //www.scielo.br/scielo.php?script=sci_arttext\&pid=S1981$77462013000300003 \&$ Ing $=$ pt\&tlng=pt. doi: $10.1590 /$ S198177462013000300003 
Cardoso, L. A, \& Romão, F. L. (2011). "Primeirização": um modelo pós-fordista de organização do trabalho na indústria brasileira. XV Congresso Brasileiro de Sociologia (SBS), Curitiba.

Dal Rosso, S. (2011). Tempo de Trabalho. In A.D. Cattani \& L. Holzmann (orgs), Dicionário de Trabalho e Tecnologia (pp. 418423). Porto Alegre: Zouk.

Dias, S. de O. M. (2015). Trabalhadores terceirizados e luta sindical. Sociologias, 17(38), 314-324. Recuperado em 01 de junho de 2015,

http://www.scielo.br/scielo.php?script=sci_arttext\&pid=S151745222015000100314\&lng=pt\&tlng=pt doi: 10.1590/15174522017003842

Ferreira, M. C. (2008). A ergonomia da atividade se interessa pela qualidade de vida no trabalho? Reflexões empíricas e teóricas. Cadernos de Psicologia Social do Trabalho, 11(1), 83-99.

Ferreira, M. C. (2009). Inventário de avaliação de qualidade de vida no trabalho (IA_QVT): Instrumento de Diagnóstico e Monitoramento de QVT nas Organizações. In Anais da 61 a Reunião da Sociedade Brasileira para o Progresso da Ciência (SBPC), Manaus.

Ferreira, M. C. (2011). A ergonomia da atividade pode promover a qualidade de vida no trabalho? Reflexões de natureza metodológica. Revista Psicologia: Organizações e Trabalho, 11(1), 8-20.

Ferreira, M. C. (2012). Qualidade de vida no trabalho. Uma abordagem centrada no olhar dos trabalhadores ( $2^{\underline{a}}$ ed.). Brasília: Paralelo 15.

Ferreira, M. C. (2015a). Primeirização da SST. Crescimento da terceirização será pior para o emprego de qualidade. Revista Proteção, 80-80.

Ferreira, M. C. (2015b). Apresentação. In I. M. R. Taveira, A. C. Limongi-França, \& M. C. Ferreira (Orgs.), Qualidade de Vida no Trabalho: estudos e metodologias brasileiras (pp. 131-132). Curitiba: CRV.

Ferreira, M. C., \& Torres, C. C. (2015). Qualidade de Vida no Trabalho (QVT): uma alternativa em ergonomia da atividade para mudança sustentável nas organizações. In I. M. R. Taveira, A. C. Limongi-França, \& M. C. Ferreira (Orgs.), Qualidade de Vida no Trabalho: estudos e metodologias brasileiras (pp. 159-169). Curitiba: CRV.

Finazzi-Santos, M. A., \& Siqueira, M. V. S. (2011). Considerações sobre trabalho e suicídio: um estudo de caso. Revista Brasileira de Saúde Ocupacional, 36(123), 71-83. Recuperado em 01 de junho de 2015, de http://www.scielo.br/scielo.php?script=sci_arttext\&pid=S0303- 
76572011000100007\&lng=pt\&tlng=pt. doi: 10.1590/S030376572011000100007

Galeazzi, I., \& Holzmann, L. (2011). Precarização do Trabalho. In A. D. Cattani \& L. Holzmann (orgs), Dicionário de Trabalho e Tecnologia. (pp. 259-265). Porto Alegre: Zouk.

Garcia, S. R. (2011). Terceirização. In A. D. Cattani \& L. Holzmann (orgs), Dicionário de Trabalho e Tecnologia. (pp. 423-426). Porto Alegre: Zouk.

Hirata, H. (2011). Tendências recentes da precarização social e do Trabalho: Brasil, França, Japão. Caderno CRH, ( $\mathrm{n}$ o especial), 24(1), 15-22. Recuperado em 28 de agosto de 2015 de http://www.scielo.br/pdf/ccrh/v24nspe1/a02v24nspe1.pdf

Jesus, G. M. de, Mota, N. M., \& Jesus, É. F. A. de. (2014). Risco cardiovascular em policiais militares de uma cidade de grande porte do Nordeste do Brasil. Revista Brasileira de Ciências do Esporte, 36(3), 692-699. Recuperado em 01 de junho de 2015, de

http: //www.scielo.br/scielo.php?script=sci_arttext\&pid=S0101-

32892014000300692\&lng=pt\&tlng=pt. doi: $10.1590 / 2179$ 325520143630017

Lago, R. R., Cunha, B. S., \& Borges, M. F. de S. O. (2015). Percepção do trabalho docente em uma universidade da região norte do Brasil. Trabalho, Educação e Saúde, 13(2), 429-450. Recuperado em 01 de junho de 2015, de http://www.scielo.br/scielo. php?script=sci_arttext\&pid=S198177462015000200429\&lng=pt\&tlng=pt. doi: 10.1590/19817746-sip00049

Laville, A. (1993). L'ergonomie (5ème édition). Paris: PUF.

Leite, M. P. (1994). Reestruturação produtiva, novas tecnologias e novas formas de gestão da mão-de-obra. In B. C. A. Oliveira (Org.), O mundo do Trabalho. Crise e mudança ao final do século. São Paulo: Scritta.

Magalhães, E., Oliveira, Á. C. M. de S., Govêia, C. S., Ladeira, L. C. A., Queiroz, D. M., \& Vieira, C. V. (2015). Prevalence of burnout syndrome among anesthesiologists in the Federal District. Revista Brasileira de Anestesiologia, 65(2), 104-110. Recuperado em 01 de junho de 2015, de http://www.scielo.br/scielo. php?script=sci_arttext\&pid=S003470942015000200104\&lng=pt\&tIng=en. $\quad$ doi: 10.1016/j.bjan.2013.07.016

Marcelino, P. (2007). Afinal, o que é terceirização? Em busca de ferramentas de análise e de ação política. Revista Pegada, 8(2). Recuperado em 06 de julho de 2015 de http://revista.fct.unesp. br/index. php/pegada/article/view/ 1640 /1570 
Marcelino, P., \& Cavalcante, S. (2012). Por uma definição de Terceirização. Caderno CRH, 25(65), p. 331-346. Recuperado em 28 de agosto de 2015 da SciELO (Scientific Eletrocnic Library On line) http://www.scielo.br/scielo. php?pid=s010349792012000200010\&script=sci_arttext

Miranda, F. F. (2010). Fontes de mal-estar no trabalho e estratégias de mediação no contexto do serviço público: desafios e perspectivas para a Qualidade de Vida no Trabalho. Monografia de Especialização em Gestão Universitária. Faculdade de Economia, Administração, Contabilidade e Ciência da Informação e Documentação, Universidade de Brasília, Brasília.

Organización Internacional del Trabajo (OIT) (2013). La prevención de las enfermedades profesionales. Primera edición. Genebra: Autor.

Projeto de Lei n. 4330 de 26 de outubro de 2004. (2004). Dispõe sobre os contratos de terceirização e as relações de trabalho deles decorrentes. Câmara dos Deputados da República Federativa do Brasil. Recuperado em 04 de maio de 2015, de http://www.camara.gov.br/proposicoesWeb/prop_mostrarintegr a; jsessionid=1852D523B1F30205BEE774FB249618E5. proposico esWeb1? codteor $=246979 \&$ filename $=P L+4330 / 2004$

Ratinaud, P. (2009). IRAMUTEQ: Interface de R pour les Analyses Multidimensionnelles de Textes et de Questionnaires [Computer software]. Recuperado de http://www.iramuteq.org

Santos, M. A. F., Siqueira, M. V. S., \& Mendes, A. M. (2011, agosto). Sofrimento no trabalho e imaginário organizacional: ideação suicida de trabalhadora bancária. Psicologia \& Sociedade, 23(2), 359-368.

Schmidt, D. R. C., Paladini, M., Biato, C., Pais, J. D., \& Oliveira, A. R. (2013, fevereiro). Qualidade de vida no trabalho e burnout em trabalhadores de enfermagem de Unidade de Terapia Intensiva. Revista Brasileira de Enfermagem, 66(1), 13-17. Recuperado em 01 de junho de 2015 de http://www.scielo.br/scielo.php?script=sci_arttext\&pid=S0034$71672013000100002 \& \operatorname{lng}=$ pt\&nrm =iso

Sennett, R. (2012). A corrosão do caráter: O desaparecimento das virtudes com o novo capitalismo. Rio de Janeiro: BestBolso.

Wisner, A. (1984). Por dentro do Trabalho. Ergonomia: método e técnica. São Paulo: Oboré.

Wisner, A. (1994). A inteligência no trabalho: textos selecionados de Ergonomia. São Paulo: Fundacentro.

\section{Endereço para correspondência}

Camila Costa Torres

Universidade Federal do Rio Grande do Norte (UFRN)

Departamento de Psicologia - CCHLA 
Lagoa Nova, Campus Universitário, CEP 59078-970, Natal - RN, Brasil

Endereço eletrônico: pcamilatorres@gmail.com

\section{Mário César Ferreira}

Universidade de Brasília (UnB)

Instituto de Psicologia, Campus Darcy Ribeiro

Asa Norte, CEP 70910-900, Brasília - DF, Brasil

Endereço eletrônico: ferreiramariocesar@gmail.com

\section{Rodrigo Rezende Ferreira}

Universidade de Brasília (UnB)

Instituto de Psicologia, Campus Darcy Ribeiro

Asa Norte, CEP 70910-900, Brasília - DF, Brasil

Endereço eletrônico: ferreirarods@gmail.com

Recebido em: 17/02/2016

Reformulado em: 24/07/2016

Aceito para publicação em: 25/09/2016

\section{Notas}

* Psicóloga (Universidade de Brasília - UnB /1999), mestre (2001) e doutora (2007) em Psicologia, com ênfase em Ergonomia (também pela UnB). Docente de nível superior desde 2001, ministrando disciplinas e supervisionando estágios em Psicologia do Trabalho e das Organizações, Ergonomia e Gestão de Pessoas. Experiência na área de Psicologia do Trabalho e das Organizações, com ênfase em Ergonomia da Atividade, Ergonomia Aplicada à Informática e Ergonomia da Atividade Aplicada à Qualidade de Vida no Trabalho. Professora Adjunta da Universidade Federal do Rio Grande do Norte- UFRN, desde 2009. Professora de Pós-graduação Lato e Stricto Sensu. Membro do Grupo de Estudos e Pesquisas sobre o Trabalho - GEPET/UFRN e do Grupo de Estudos e Pesquisas em Ergonomia Aplicada ao Setor Público - ErgoPublic/UnB.

** Doutor pela École Pratique des Hautes Études (EPHE, França), com pósdoutorado Université Paris 1 Sorbonne (França) em Ergonomia da Atividade Aplicada à Qualidade de Vida no Trabalho. Professor associado IV no Departamento de Psicologia Social e do Trabalho do Instituto de Psicologia da Universidade de Brasília (UnB) e no Programa de Pós-Graduação em Psicologia Social, do Trabalho e das Organizações (PPG-PSTO) do Instituto de Psicologia. Coordenador do "GT Trabalho e Saúde" da Associação Nacional de Pesquisa e Pós-Graduação em Psicologia (ANPEPP). Coordenador do Grupo de Pesquisa no Diretório do CNPq "Desenvolvimento de Pessoal e Qualidade de Vida no Trabalho no Setor Público (DViTra)", do "Núcleo de Ergonomia da Atividade, Cognição e Saúde (ECoS)", do Grupo de Estudos em Ergonomia Aplicada ao Setor Público (ErgoPublic). É bolsista de produtividade em pesquisa do CNPq - Nível 2, onde executa projeto (20142017) na temática "Contexto de Trabalho e Práticas de Gestão em Organizações Brasileiras: Impactos Sobre a Qualidade de Vida no Trabalho". É autor do livro "Qualidade de Vida no Trabalho. Uma Abordagem Centrada no Olhar dos Trabalhadores" (2012) Editora Paralelo 15, co-autor do livro: "Trabalho e riscos de adoecimento: o caso dos auditores-fiscais da Previdência Social brasileira" (2003) Edições Ler, Pensar, Agir " LPA, co-organizador dos livros: "Trabalho e Saúde: Cenários, Impasses e Alternativas no Contexto Brasileiro" (2015) Editora Opção; "Qualidade de Vida no Trabalho: Estudos e Metodologias Brasileiras." (2015) Editora CRV, "Qualidade de Vida no Trabalho: Questões Fundamentais, Perspectivas de Análise e Intervenção" (2013) Editora Paralelo 15 e "Dominação e Resistência no Contexto Trabalho-Saúde" (2011) Editora Makenzie.

*** Professor adjunto no Departamento de Administração (ADM) e no Programa de Pós-Graduação em Administração (PPGA / Mestrado Profissional em Administração 
Pública) da Universidade de Brasília (UnB). Administrador pela Universidade Federal de Mato Grosso do Sul (UFMS, 2004). Mestre (2009) e Doutor (2014) em Psicologia Social, do Trabalho e das Organizações pela UnB. Pesquisador do Grupo de Estudos e Pesquisas sobre a Gestão de Pessoas na Administração Pública (GEPAP, ADM/PPGA, UnB) e do Grupo de Estudos em Ergonomia Aplicada ao Setor Público (ErgoPublic, PSI/PSTO, UnB). Desenvolve pesquisas e tem interesse nas áreas de Aprendizagem no Trabalho, Educação Corporativa, Qualidade de Vida e Bem-Estar no Trabalho, Administração Pública, Modelagem Multinível, Método em Pesquisa Organizacional. 